\title{
Pit Slope Design and Structural Analysis at the Jericho Diamond Mine Utilising Digital Photogrammetric Mapping
}

\author{
J.I. Mathis Zostrich Geotechnical, USA
}

\begin{abstract}
Characterization of the spatial characteristics of geologic structures (continuity, centre density, and orientation) is of tremendous importance to rock slope design. While rock fabric mapping has been utilized for bench design, collection of data sufficient in both accuracy and quantity to characterize the fabric spatial characteristics for geotechnical design has always been a problem. It is even more difficult to collect spatial characteristic data relating to intermediate scale faults, shears, and continuous joints. This has hindered the application of statistical structural modelling techniques to interramp and overall slope design. The advent of digital photogrammetric methods allows one to overcome many of the slope scale and data coverage limitations that restricted such methods.

The Jericho Diamond Mine, owned and operated by Tahera Diamond Corporation, is located in Nunavut, Canada. The host rocks for the diamondiferous kimberlite consist primarily of massive granitic rocks. Collection of adequate statistically valid samples of the spatial characteristics of both the smaller scale discontinuities (joints) and larger scale discontinuities (faults/shears) is difficult utilizing standard mapping techniques as the mean trace length of the joints can approach the presently mined bench height. Instead, digital photogrammetric mapping of the pit walls was conducted utilizing ADAM Technology's 3DM Analyst photogrammetric software. The resulting DTM's, mapped discontinuities, and draped images were imported into Maptek's Vulcan software where major structural zones/faults were modelled. Zostrich Geotechnical's discontinuity data reduction and modelling software was applied to statistically quantify/predict bench face angle distributions and to determine the probability of overall and interramp pit wall failures.
\end{abstract}

\section{Introduction}

The Jericho Diamond Mine, owned and operated by Tahera Diamond Corporation, is located in Nunavut, Canada approximately $420 \mathrm{~km}$ north-northeast of Yellowknife. This open pit mine will be excavated in several stages, allowing multiple exposures of the pit slope rocks in all orientations. The initial stage pit, examined and imaged in October 2006, is approximately $350 \mathrm{~m}$ in diameter at the crest, with a depth of about $50 \mathrm{~m}$ (Figure 1). The ultimate pit, after three stage expansions, is to be about $400 \mathrm{~m}$ in diameter and approximately $300 \mathrm{~m}$ deep (Figure 2 ).

Utilising standard field mapping techniques, it would be difficult to collect accurate data to adequately describe the spatial characteristics (orientation, centre density, and radius) of the rock fabric (joints). This is due, in part, to the fact that the mean trace length of the joints can approach the presently mined bench height of $10 \mathrm{~m}$. Larger structures (faults/shears) may traverse several benches. The characteristics of these major features, and intervening bench geometry, can make it difficult to trace the features from bench to bench with standard mapping, if slope access is even available.

The advent of digital photography, together with the requisite powerful photogrammetric programs for image reduction, makes it possible to create detailed and accurate digital terrain models (DTM's) of the rock face, either natural or pit slope. These DTM's, when coupled with registered and draped digital images, allow the engineer to accurately map small scale rock fabric, conduct large scale structural interpretations, examine failure modes, and verify bench and slope design. 


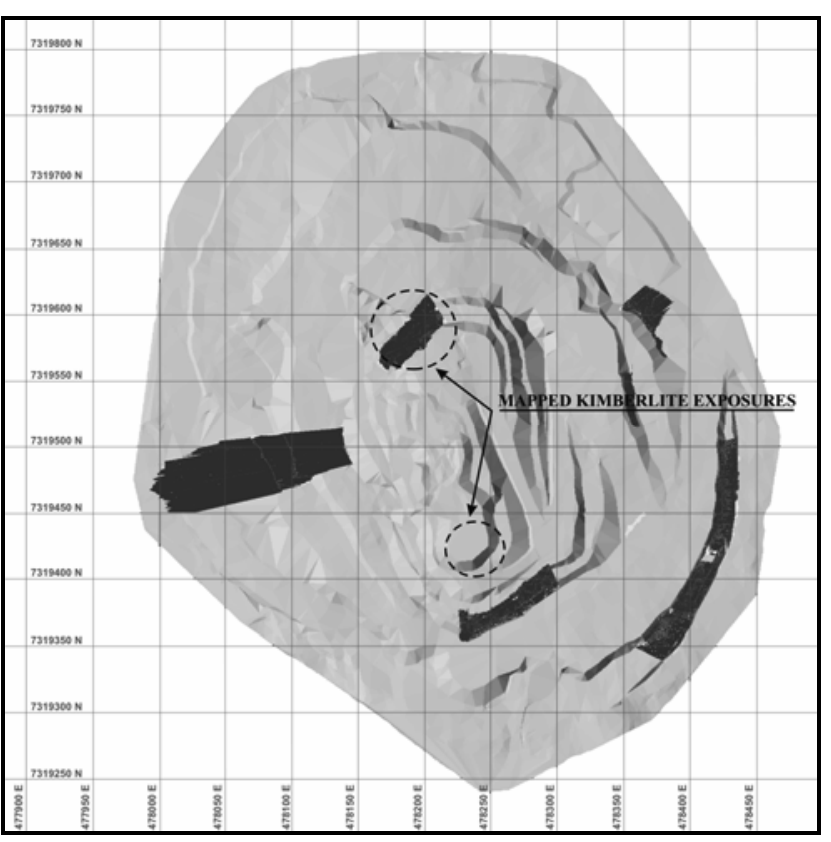

Figure 1 Photogrammetric mapping locations

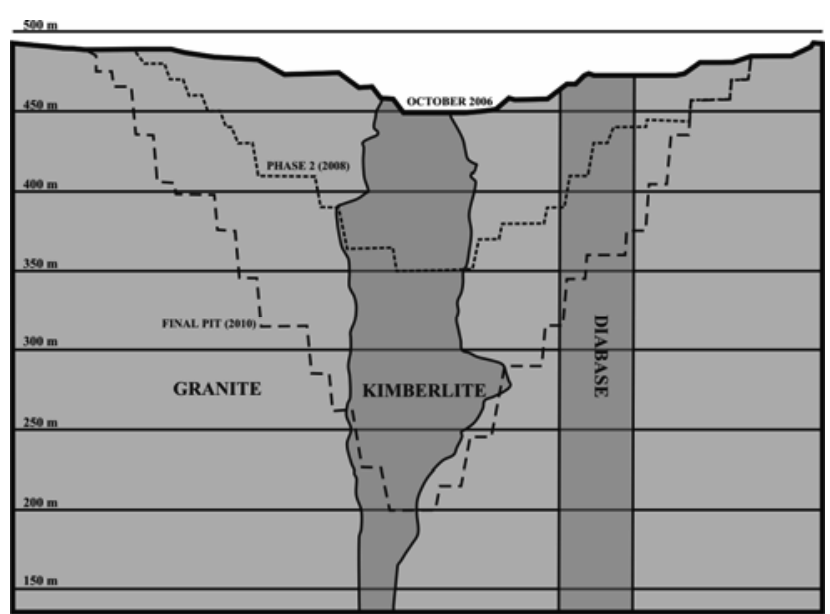

Figure 2 Generalised east-west section

\section{Photogrammetric data collection}

Image locations were chosen in the Jericho pit based primarily on clean slope exposure. In other words, it was necessary to choose areas where relatively clean rock faces could be mapped. Once the image location was determined, camera locations were located such that an approximate 1:3 camera base to distance ratio was obtained. All images were collected with a Canon 20D camera ( $8.4 \mathrm{Mp})$ using either $24 \mathrm{~mm}, 50 \mathrm{~mm}$, or $135 \mathrm{~mm}$ fixed focal length objectives. The camera was mounted on a survey tripod, using a specialized adaptor. After the photographs were taken from a point, the camera was replaced with a Sokkia Set R3 reflectorless total station and the face control points surveyed. Camera locations were surveyed by the mine surveyor so that they were fixed in the mine grid. The image control points were then converted to mine coordinates.

The purpose of the images was determined prior to photography. If possible, high resolution images were taken to provide highly accurate images (and later DTM models) for both major structure determination and rock fabric mapping. However, at times, lower resolution imagery was utilised to reduce the model size but yet provide a good overview of the pit wall for major structure mapping.

Data reduction was carried out utilising ADAM Technology's 3DM Analyst photogrammetric software. This provided accurate and very repeatable DTM models. The latter is illustrated by a test where two benches were photographed at close range $(40 \mathrm{~m})$ with a $24 \mathrm{~mm}$ objective, then later from across the pit $(200 \mathrm{~m}+)$ with a $135 \mathrm{~mm}$ objective. The resulting models were essentially indistinguishable.

As can be seen in Figure 1, the locations of the images (October 2006) do not cover the entire stage pit. However, as mining progresses, additional images will be obtained. These should provide nearly complete coverage of the pit as a function of time, both with respect to vertical depth and as well as into the slope. The three dimensional layering of the resultant images and DTM's will provide an excellent database for modelling geologic structures and overall slope performance.

\section{Data analysis and reduction}

\subsection{Rock fabric mapping (photogrammetric)}

Discontinuity locations, orientations, and continuity were obtained from the DTM's and associated draped images created in ADAM Technology's 3DM Analyst photogrammetric software. Mapping was conducted 
manually, on screen, by rotating, delineating, and saving each individual discontinuity manually. This method was chosen as the software provides an excellent interface for manually determining points on structural planes. Automatic face picking, while available, was deemed too unreliable for determining structure continuity, as the method cannot accurately determine what is a discontinuity, nor the surface's trace length, without intelligent intervention by the engineer.

Discontinuity mapping results obtained from digital photogrammetric software have been compared by this author, at other sites, between oriented core, physical face mapping and a combination of the two. In general, the match has been good to excellent. In fact, the digital mapping has highlighted some biases that have not been addressed in standard mapping due to its greater coverage.

The discontinuity orientation data obtained from photogrammetric mapping from all imaged areas were plotted on stereonets to determine if any obvious differences (structural domain effects) were apparent. For the case of the Jericho pit, no apparent structural domain bounds were observed, although local effects from faulting were noted as increased discontinuity frequency and trace length paralleling nearby faults.

A cell window (Mathis, 1988) was then inscribed on the resulting mapped 'face' (Figure 3). The structures were characterised as to truncation characteristics (single, double, or no truncation) of the trace relative to the inscribed mapping window.

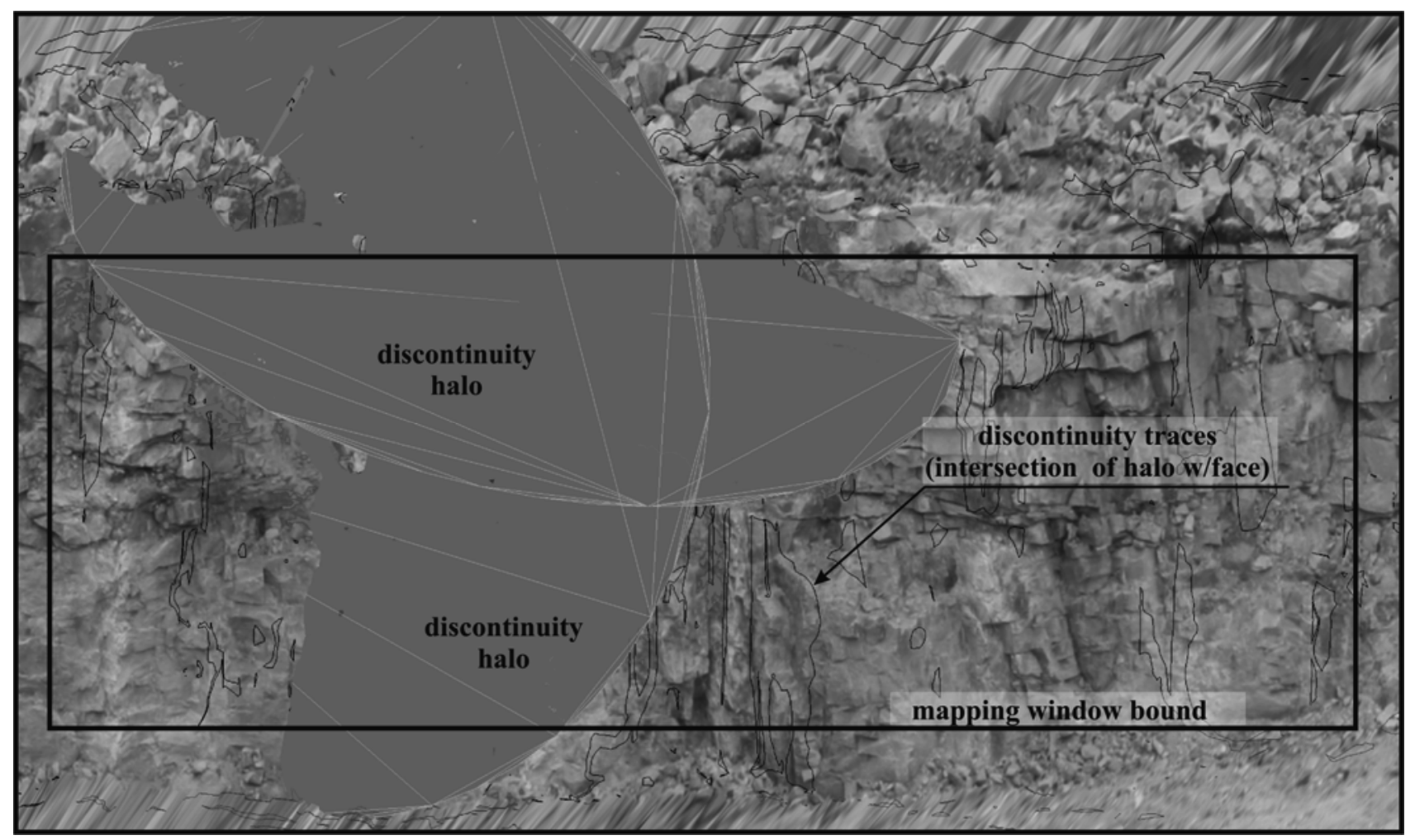

Figure 3 Window (cell) mapping of photogrammetric DTM model

Discontinuity set bounds were determined manually from stereonets for the combined discontinuity data. Trace lengths and joint centre densities (Mathis, 1988) were calculated, by individual described set, for each mapping window. The resulting data were combined to produce a numerical description of the rock fabric (small scale discontinuities) spatial characteristics amenable for inclusion in the slope design work to follow.

Joint spatial characteristics of the rock mass, as determined from the photogrammetric mapping, are presented in Figure 4 for the granite and kimberlite. These results include the probability occurrence, or the number of cells in which the discontinuity set actually was found. This probability of occurrence is of considerable import to slope design work due to the fact that some weaker sets will improperly influence design as they may not be ubiquitous. The probability of occurrence, as described aerially as a function of the window size, can be utilised to compensate for this potential undue influence. 


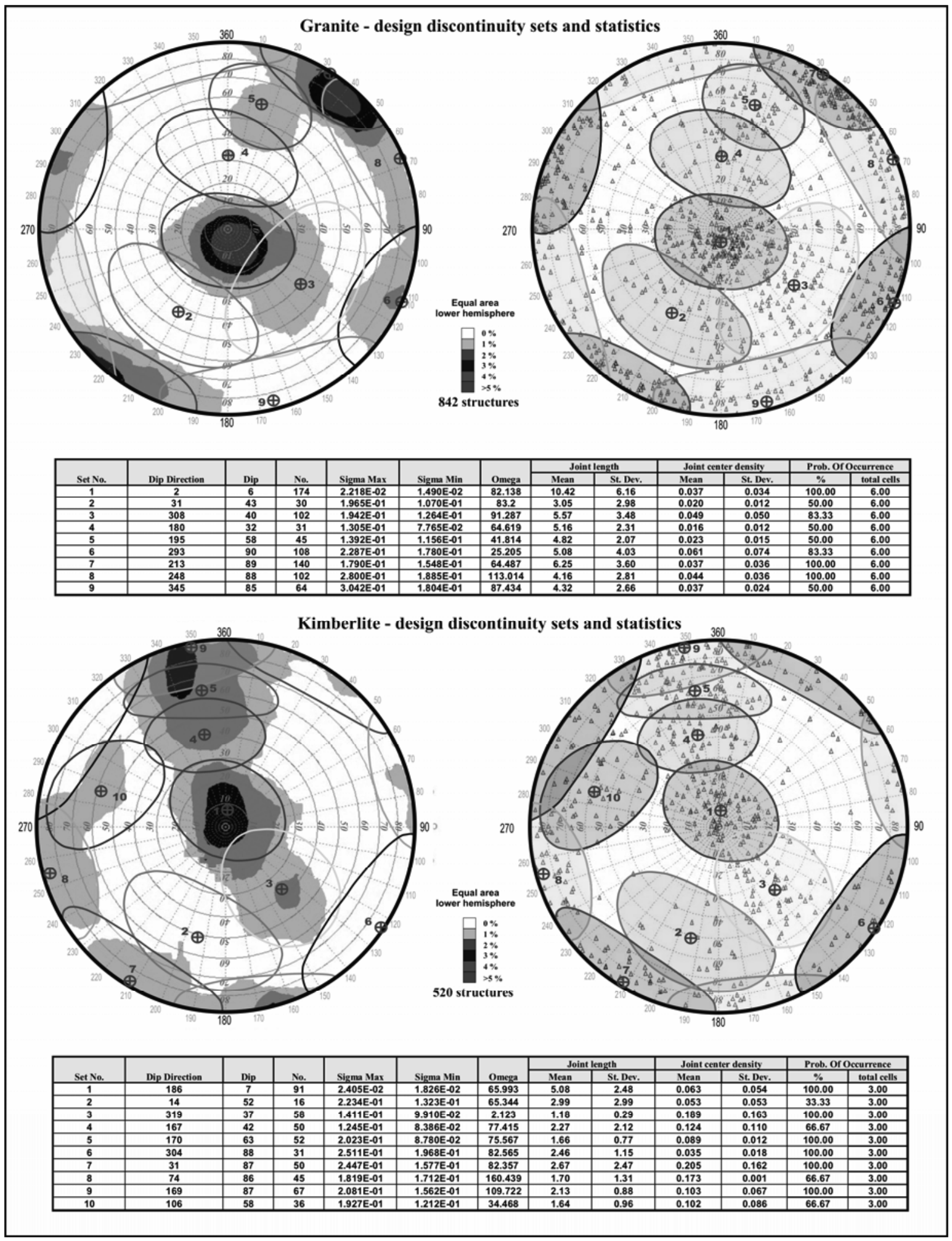

Figure 4 Rock fabric characterisation as determined from photogrammetric mapping

Note that in Figure 4, sigma max and sigma min describe the major and minor axes of a bivariate normal distribution for the orientation distribution on a tangent plane to the plotting hemisphere. Omega is the angular rotation of this bivariate distribution to the coordinate system's X axis. Further, centre density is the number of joint centres per volumetric unit of rock measured (here in metres), and the length is the mean trace length of the discontinuity set. 


\subsection{Major structure determination (photogrammetric)}

Major structures, and structural zones, were determined from the photogrammetric mapping as well. The methodology utilised is as follows:

- The structural database was sorted by discontinuity trace length. Structures less than about two-third of the bench height were discarded.

- The censored database was sorted by discontinuity set.

- All the discontinuities from one set were then plotted, based on their mapped spatial location, on the pit walls. An example is given in Figure 5 (plotting in Maptek's Vulcan 6). Note the concentration of structures from Set 2 is essentially a single band on the south wall of the stage pit.

This zoned clustering of longer discontinuities has been noted on several projects using the photogrammetric mapping method. It is only by using such a method that one can obtain the three dimensional data for such a spatial analysis of longer structures. In almost all cases, the zoning relates to faults, shears, or zones of anatomising, continuous structures. While the exact type of major structure may differ, these features generally describe a continuous weakness plane in the rock mass.

In some cases, as the bench faces were examined by the author during the site visit, attributes regarding infill, thickness, waviness, etc. could be attributed to specific geologic features. Other major structures were not as obvious during the field examination, appearing as very continuous joints at bench scale. As noted previously, further examination of the photogrammetrically determined structures on the pit scale indicated that the features were apparent, just not obvious with field mapping.

Note that this is not the final determination for major structure in the pit area. It is obvious that not all structures influencing pit slope stability will be evident in the stage pit. However, it is likely that major structures, presently undiscovered, that may impact pit wall stability will have similar orientations to those depicted. Therefore, an oriented core program has been designed to examine the pit walls at depth in the orientations where particularly adverse structures may exist. In addition, while the major structures provided in Figure 6 have generic orientations at present, they can be adjusted on an individual basis as mining progresses, utilising additional photogrammetric images, field mapping, and oriented core results.

\section{Pit slope design}

The diamond mines of the Canadian Shield are somewhat unique in terms of slope design. The rock mass in which the pipes are emplaced is generally massive and strong, with very continuous fracture systems. In addition, the mining target is a carrot shaped plug of kimberlite decreasing in size with depth. Fuel is at a premium as it must be transported into the mine site on a seasonal ice road. The combination of these factors dictates that the overall pit slope must be relatively steep for the projects to be economically viable.

The factors that generally work in favour of steep slopes in this area are the relatively wide spacing of major structures, and the generally favourable orientations of the geologic structures.

For this design, as for all Zostrich Geotechnical designs, the following interrelated design areas (and potential controlling slope angles) were examined: bench scale (face angle and catch bench width), interramp, and overall slope.

\subsection{Bench scale design}

The geometry created by the catch bench width, bench height, and face angle will determine one of three design slope angles - the catch bench determined overall slope angle. In the case of the Northwest Territory diamond mines this slope angle is often the governing design angle for the pit walls. As such, considerable import is placed on accurately determining the design bench face angles.

The initial Jericho stage pit was excavated utilizing a $7.5 \mathrm{~m}$ high single bench. The present excavated bench height is $10 \mathrm{~m}$, with plans for $20 \mathrm{~m}$ (double bench) and $30 \mathrm{~m}$ (triple bench) heights for future stages.

Catch bench face angle design, as conducted by this author, utilises a discontinuity fabric model in order to determine bench face angle reliability (Mathis, 2002). Discontinuity spatial characteristics, as presented in 
Figure 4, and obtained from photogrammetric mapping are simulated in a three dimensional, Monte Carlo generated, discontinuity model.

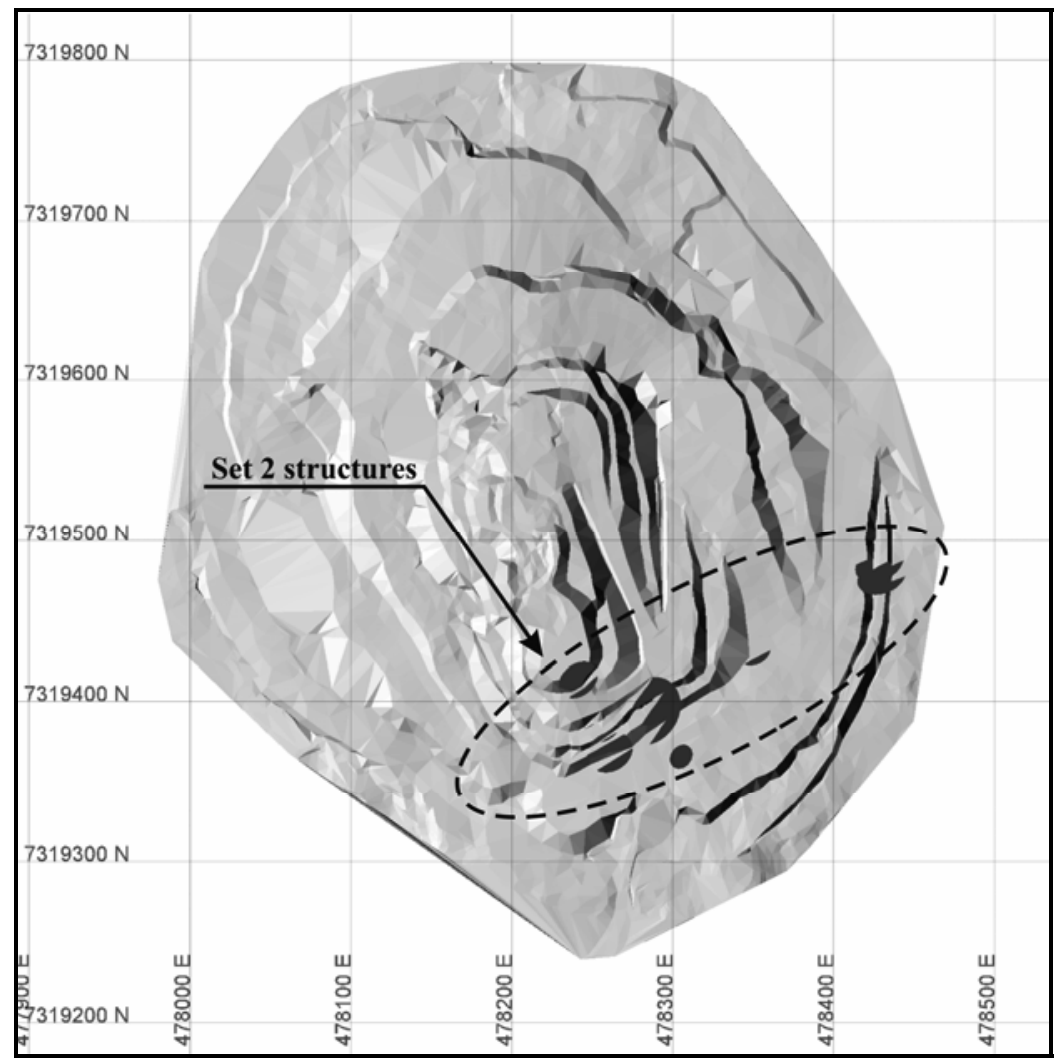

Figure 5 Major structural zone determination from discontinuity halos

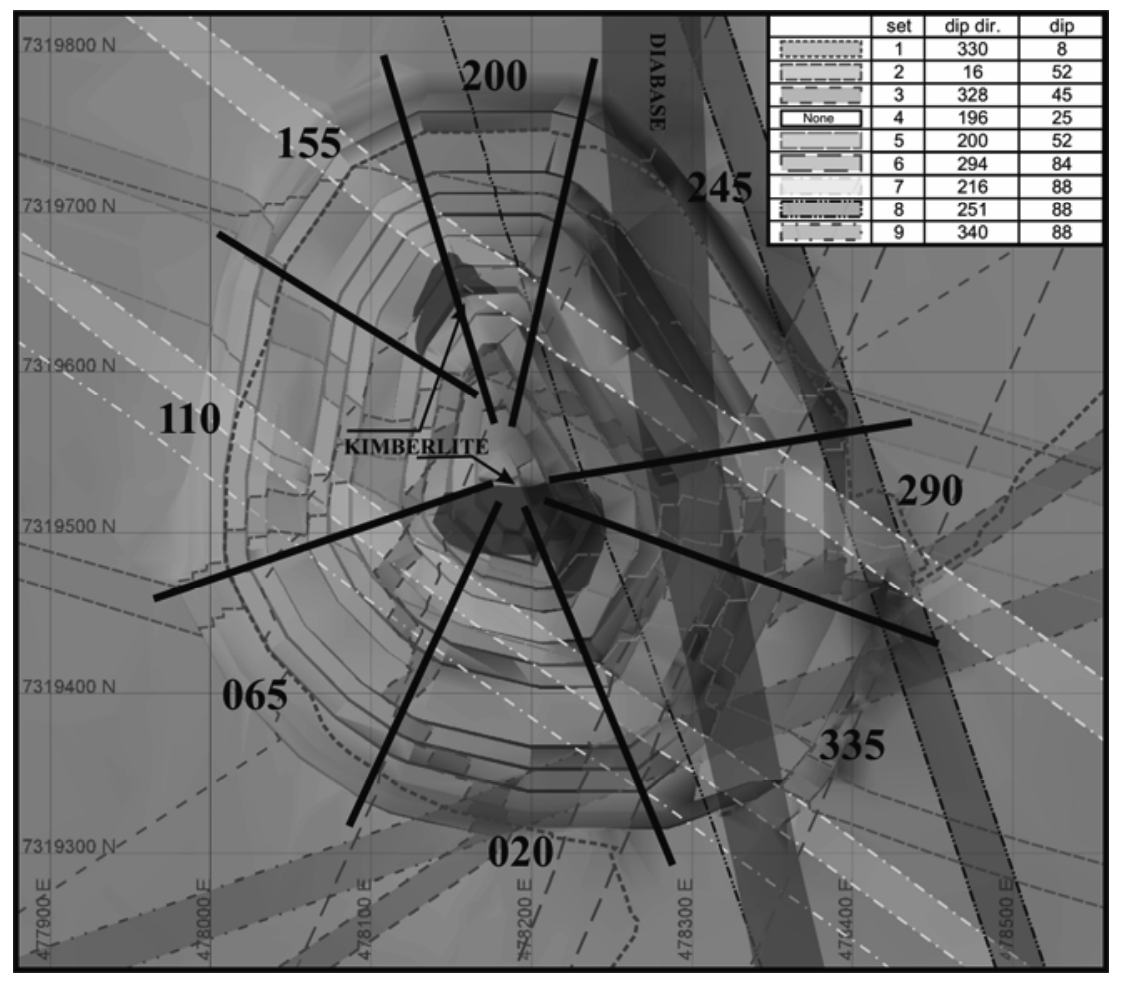

Figure 6 Major structures and design sectors, ultimate pit 
The three dimensional model is then cut by a simulated bench face (Figure 7), and statistical failure analyses conducted on the daylighting features. Only plane shear and wedge failure modes were analysed, as these tend to dominate the bench scale failures both for this, and many other, bench scale slopes. Note rock fall simulation using simulated face profiles was utilized to verify the required bench width to accommodate rock fall. However, as this article addresses structural analysis relating to slope stability design, it is not discussed herein.

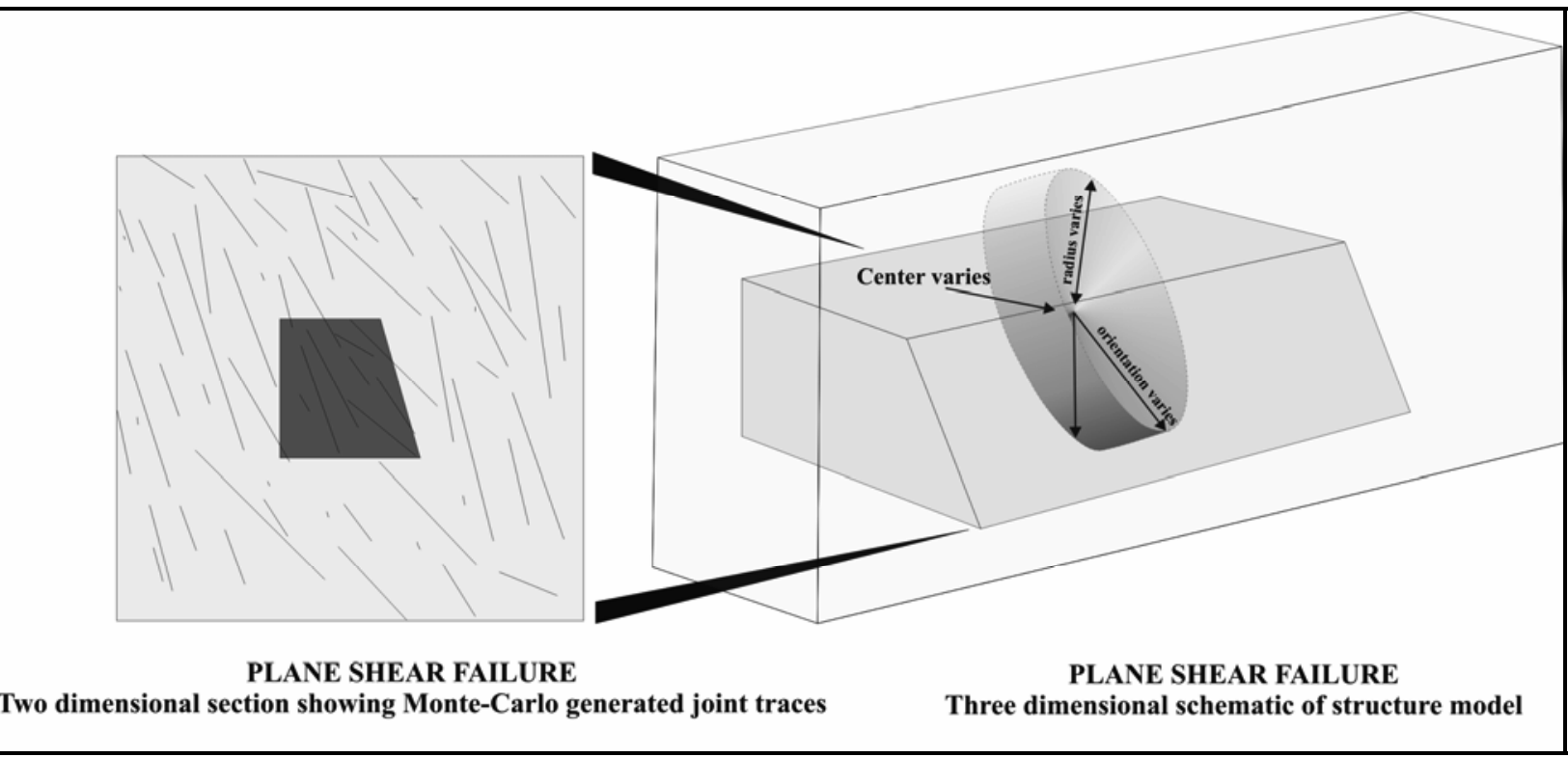

\section{Figure 7 Generalised schematic of bench face analysis, plane shear case}

Experience has shown that it is always prudent, as well as good engineering, to validate any slope design. Verification of bench scale performance utilising this methodology has been conducted using a multitude of individual face profiles obtained from surveying (Mathis and Todd, 2002). One of the advantages of utilising photogrammetric techniques is that the entire imaged slope is available for face profiling to compare with the analytical bench face and slope angles (Figure 8). While some blind areas may exist due to camera location (Figure 8), the accuracy of the slope topography is far superior to that obtained by any other easily applied methodology. This accuracy in itself can contribute to problems.

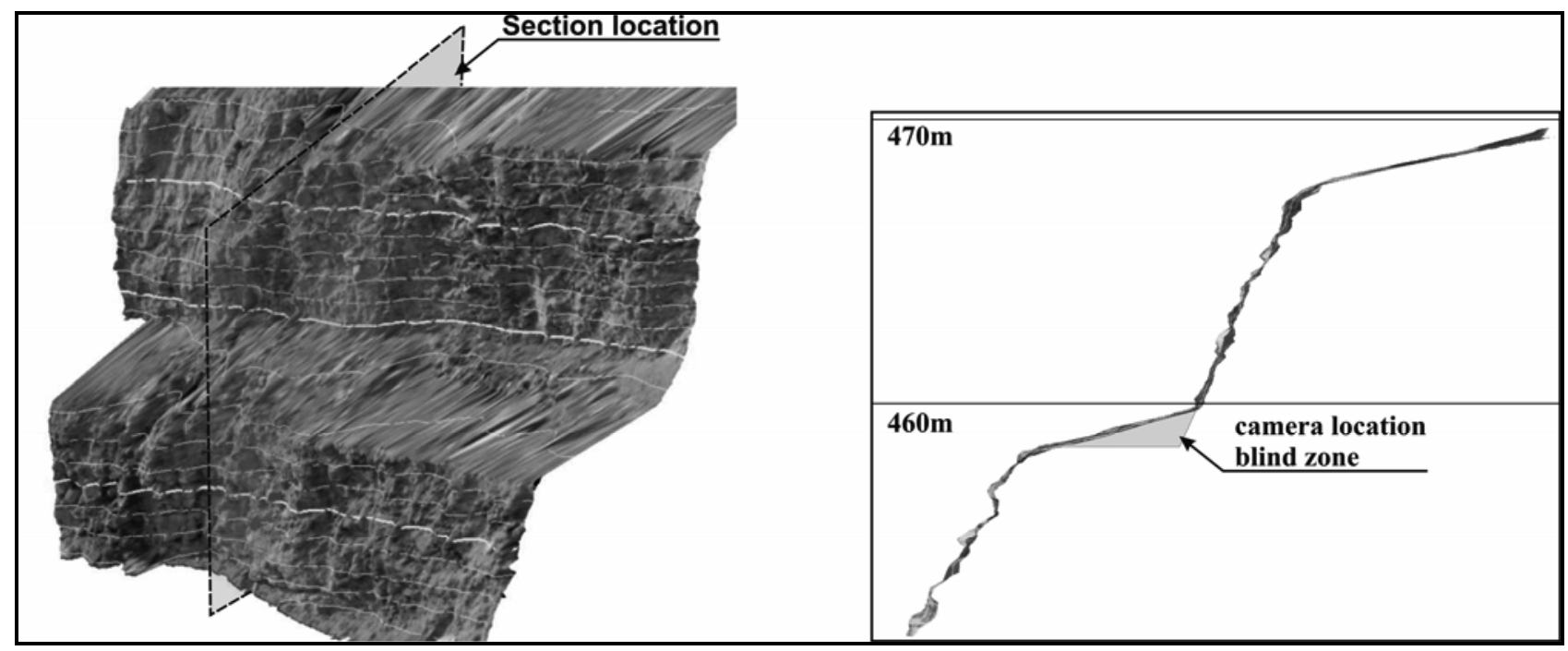

Figure 8 Contoured DTM (with draped image) and section 
The following example illustrates the latter statement. If one simply estimates the face dip with compass, a single face angle is obtained, plus or minus a few degrees. A surveyed profile, constructed from 4-10 points will provide more information about the shape of the bench, but will still generally illustrate a relatively defined toe and crest. However, when one examines the photogrammetric DTM with its thousands of points, the effects of crest round over, hard toes, and rubble accumulation at the toe all become obvious. Thus, an error range must be defined for the attained face angle. This error range, as shown in Figure 9, is dependent on the inaccuracy of the estimate determining the crest and toe of the bench. This error is obviously inherent in any other method utilised for profiling benches, it is, however, not as easily quantified as when using digital photogrammetry.

For this design, $7.5 \mathrm{~m}$ high theoretical benches were compared to those attained in the field (Figure 9). Note that the reliability providing the $\mathrm{Y}$ axis in these graphs is the likelihood that the bench face will be steeper than the face angle shown for the corresponding point on the $\mathrm{X}$ axis. These reliabilities have been determined from combination of the plane shear and wedge failures obtained from the Monte Carlo discontinuity failure simulations (Figure 7).

It must be noted that the design toe was not utilized for comparison. Instead, the actual toe of the slope, as best estimated from the photogrammetric DTM's was utilised. This would normally provide a steeper face angle for comparison than if the design toe was utilised. The analytical and theoretical curves, presented in Figure 9, are very similar in shape. In addition, they are quite similar in location in several design sectors. However, in some granitic cases, the attained angle is steeper than the model predicts. This is likely due to a slight overestimation of the discontinuity mean length for discontinuity Set 3 (Figure 4). Adjusting the mean length of this set by 0.33 standard deviations (about $0.4 \mathrm{~m}$ ) brings the model into compliance with the attained values (Figure 9). Thus, the comparison indicates that more effort should be utilised in defining Set 3 to ascertain if this is, in fact the contributing error.

The attained kimberlite curves are shallower than predicted. This is likely due to two factors. The first is that the mean discontinuity trace length may be under-represented from mapping. Loose rock on the slope made it difficult to ascertain the true continuity of some of the features. The second is that the material, although exhibiting relatively short discontinuity lengths, is quite blocky. Such material is often over excavated by the operator when cleaning the bench face. While more work is needed in defining the discontinuities in the kimberlite, it may also be that greater care will be required when blasting and excavating the final walls in this material.

One of the interesting aspects of conducting multiple height designs in a single design domain is the obvious effect of the bench height on providing a steeper design bench face angle. Figure 10 illustrates this effect.

\subsection{Interramp design}

Bench scale design is, for most part, predicated on relatively simple failure modes with low applied stresses on the sliding surfaces. The controlling geologic structures (rock fabric) can be dealt with statistically as has been done above. Overall slope design involves the overall slope stability. While failure modes may be complex, large slope areas can be isolated and evaluated as individuals.

However, interramp slope design is more much complex, incorporating intermediate faults, rock fabric, and at times, rock mass strength characteristics. It is essentially the no-man's land between the statistical fabric stability analyses for benches and the individual overall slope stability analyses.

Stability of the interramp slope is generally still controlled by relatively simple structural failure modes. Yet, when attempting to proceed utilizing similar logic as for bench design, two major problems immediately arise. The first is characterising the frequency, continuity, and location of the geologic structures that may control any potential interramp scale failures. The second is economic, as, unlike bench design, the operator must decide when an interramp scale failure occasions economic impact on the operation. Other than the obvious safety concerns, which must be addressed, this latter actually dictates the interramp slope angle chosen for design. 

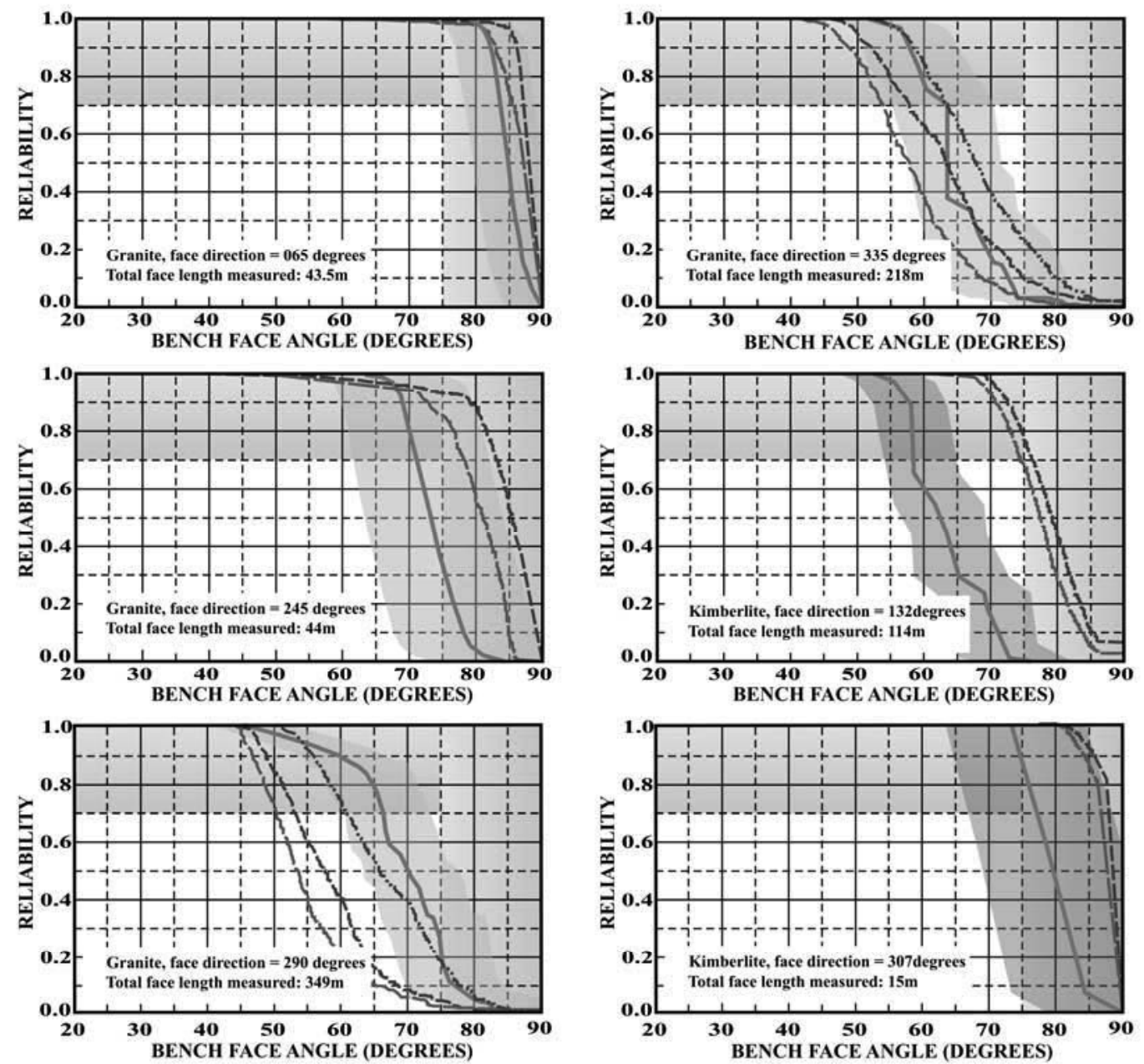

Calculated backbreak, $7.5 \mathrm{~m}$ bench height

Calculated face angle (mapped density/residual friction)

Blast affected face angle

(0.5SD increased JCD, residual friction)

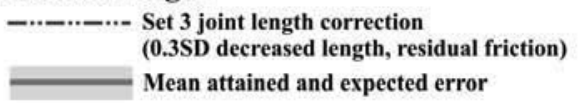

Figure 9 Comparison of attained bench face angles with theoretical

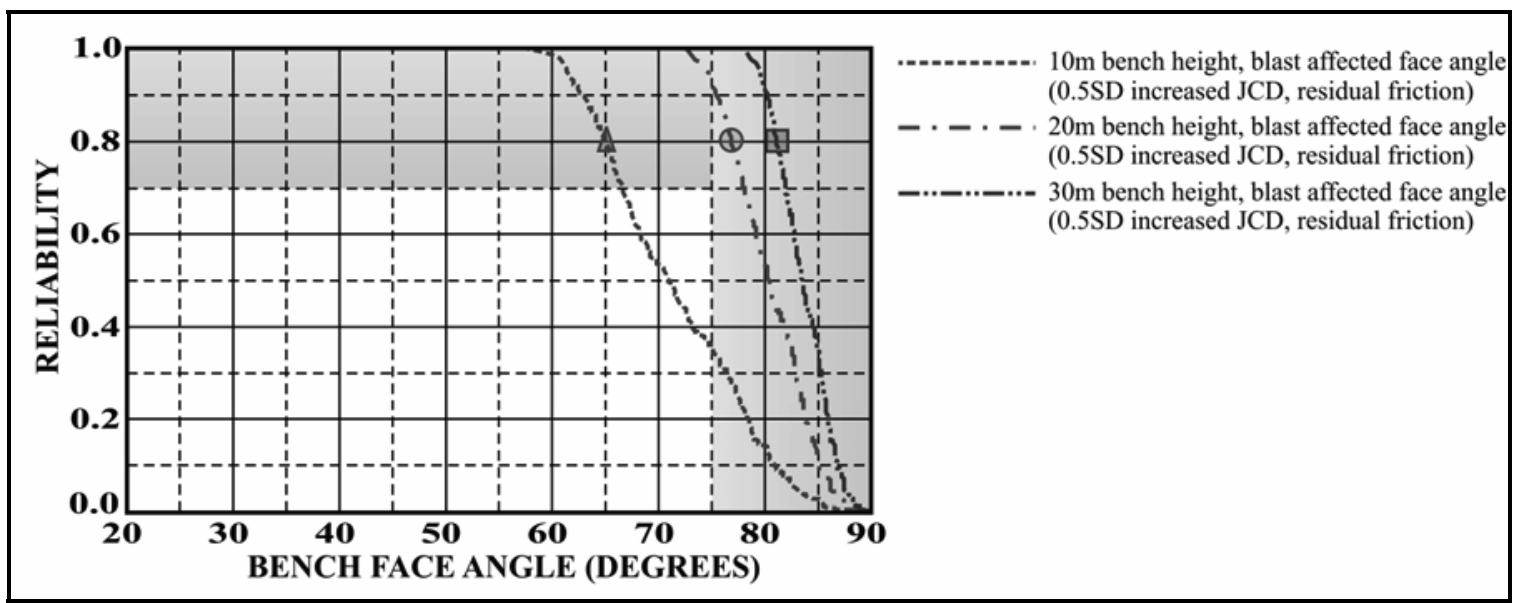

Figure 10 Effect of bench height on design bench face angle 
Once the engineer has collected information on the interramp structural features or zones, the problem arises as to how to treat them. It is theoretically possible to treat the longer features as a population. However, the distribution describing the population is somewhat of an unknown. Are we dealing with a continuum of features, from small scale rock fabric to large scale faults, as a function of some overriding distribution? Do the large scale fabric features belong to their own distinct population and distribution?

Scheduling precluded the analysis that was hoped to be presented herein. The imagery necessary from the newly excavated stage pit walls was not available at the time of this writing to statistically estimate the spatial characteristics of the intermediate scale geologic structures from the exposed interramp slope. Sufficient information was unavailable from the available images. Thus, an alternative method was chosen to complete the design.

What was done instead, for this presentation, was to determine the number of structures determining plane shear and wedge failure modes within each of the design sectors. Stability analyses were conducted on the interramp scale (70-90 m slope height) assuming continuous geologic features following the design sector derived plane shear dip, and wedge plunge, distributions (Figure 11).

From such an analysis, the expected number of interramp scale failures was determined by design sector. This provided a general guideline for the engineer, and for the operator, in order to evaluate at what interramp angles a large increase in the expected number of failures is initiated.

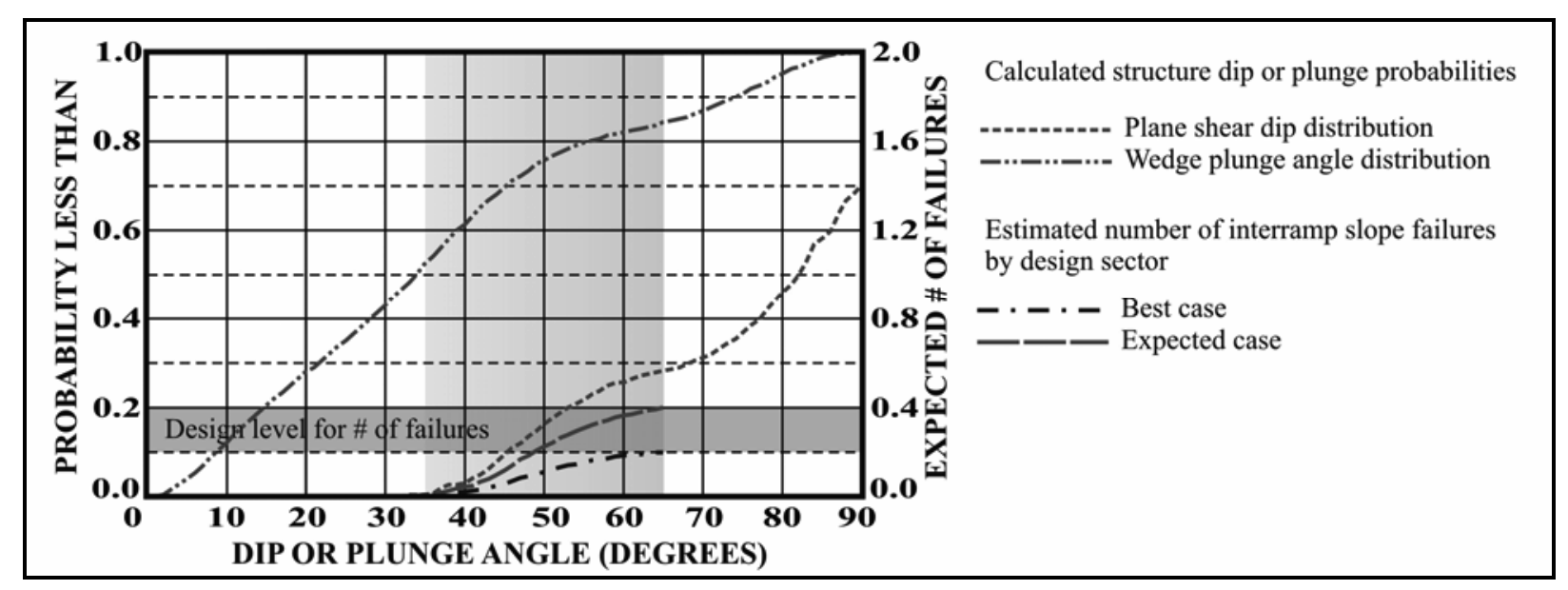

\section{Figure 11 Interramp design graph}

The final recommended design interramp angles will then be a subject of discussion between the engineer and the operator, as the decision is largely economic. For the Jericho mine, as for other diamond mines in the Northwest Territories, rock support is an option. Thus, if photogrammetric imaging and concurrent mapping are carried out as excavation progresses, it is entirely possible to support potential failures prior to the toe of the failure block being daylighted.

\subsection{Overall slope design}

Stability of the overall pit slopes at the Jericho mine will be dictated by the location of major, through going, geologic structures. If these features are located such that they define a kinematically viable failure block in the pit walls, then failure will likely occur. Otherwise, due to the relatively low overall slope heights, and high rock mass strength, rock mass failures are unlikely.

At present, based on current mapping and interpretation, no overall failure slope failure geometries are known to exist. Oriented core drilling is being conducted in the slopes to ascertain whether any such structures may exist behind the design slopes as well as to confirm the orientations and locations of faults projected from surface mapping. 


\section{Conclusions}

Photogrammetric imaging of rock slopes, both excavated and natural, is an extremely valuable tool for the rock engineer. It is so valuable that this firm requires that such imagery is obtained and properly analysed for all pit slope and rock mass characterisation projects. A flow chart as to the general progression for structural model creation utilizing this technique is found as Figure 12.

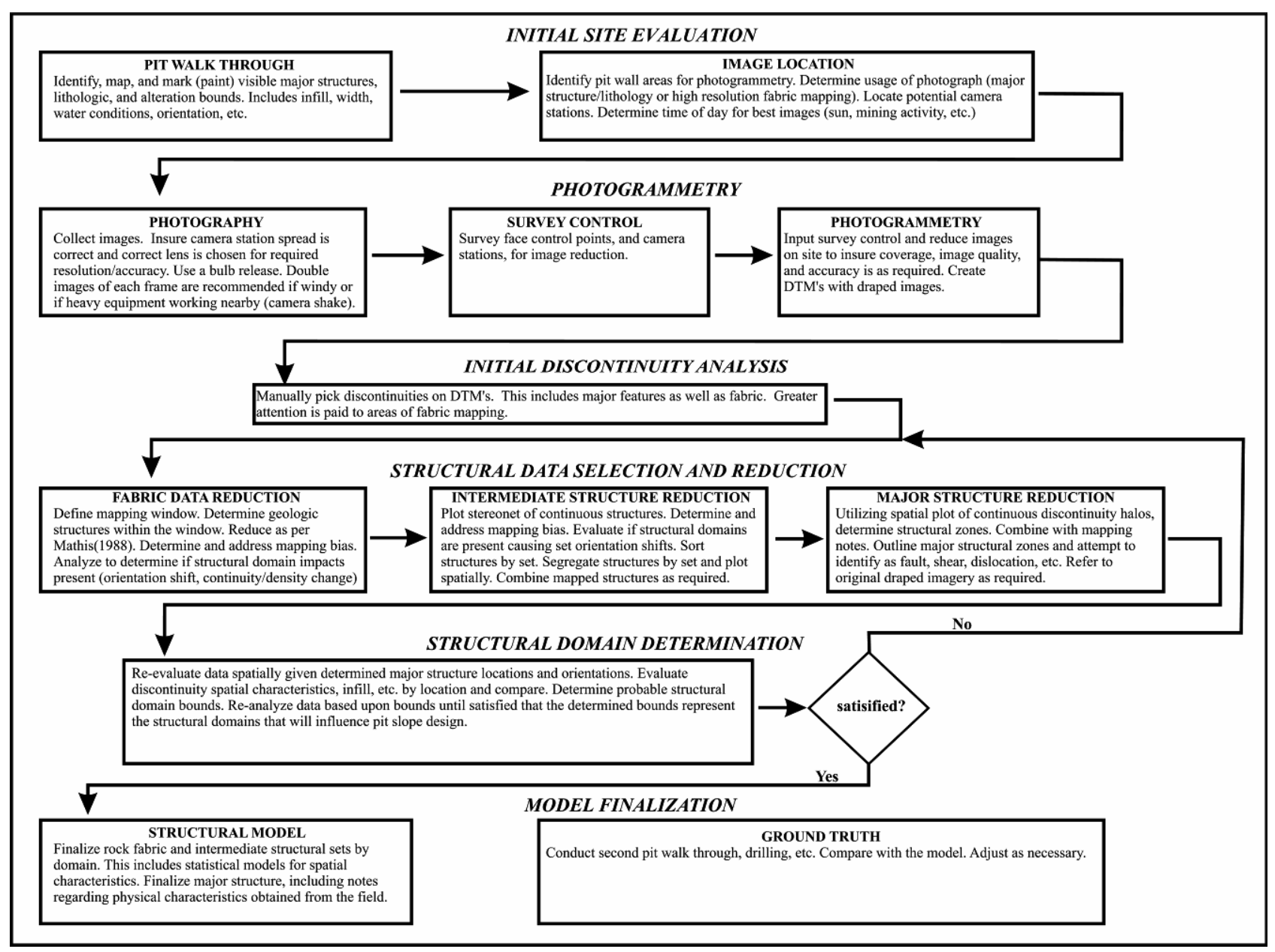

Figure 12 Flow chart for photogrammetric geotechnical model construction

The advantages are many and obvious:

- Images can be obtained with limited or no access to the mapped area, in times of good lighting, and prior to an area being covered or removed. Thus, high quality data are obtained that cannot be obtained in any other fashion.

- Geologic structures can be mapped the entire height of the bench face. Interpretation of these structures, using methods shown herein, as well as the obvious method of overlaying the DTM/image files on screen, allow major geologic structural zones to be much better delineated than is generally the case.

- Detailed fabric mapping can be conducted to provide a large number of structures with accurate continuities and orientations, with a tremendous aerial extent being covered. This latter is of importance as it better incorporates spatial joint variability across the design pit wall as compared to small scale window or line mapping.

- Profiles of the bench walls are available in accurate spatial coordinates. This allows for back analysis of failures, examination of blast damage, and comparison of actual performance with predicted performance. 
- Interramp slopes can be analysed in their entirety. This allows for the mapping of the intermediate fault structures that may control these slopes as well as allowing for comparison between actual and predicted performance.

- Multiple 'layers' of excavation and associated structures, provided by the DTM draped images can be observed in three dimensions as a function of excavation. This allows accurate interpretation of major geologic structures, as well as enables one to follow the variability of the rock fabric into the pit slope as well as to depth.

- Imagery provides a permanent three dimensional record. The images can be re-analysed as necessary, including certain image enhancement techniques, to provide additional data and to correct errors. Physical mapping does not allow this, as the face may be mined out or no longer accessible.

However, there are disadvantages as well:

- There are many biases that are inherent in discontinuity mapping, some of which have yet to be described in technical papers, with a few unique to digital photogrammetry. This has become very obvious to the author over the last year of relatively continuous photogrammetric usage. Biases can affect the orientation, continuity, and joint centre density values as a function of face bearing, face dip, face coverage, face relief, lighting angle, image resolution, etc. If these are not properly addressed, even a simple stereonet of the acquired poles may misrepresent the character of the rock. Note, however, that similar misrepresentation is frequently seen with physical mapping as well.

- Modelling of the discontinuities in the rock mass is not a simple task, even if the aforementioned biases are excluded. Therefore, if at all possible, the engineer must verify the model as frequently, and with as much detail as practically possible. This is one of the reasons for the attained versus theoretical bench face angle comparison within this report. It allows one to verify the obtained spatial characteristics are generally accurate. If not, these can be adjusted and/or additional work conducted to better describe the rock. This is a necessary step.

- Imaging is not simply taking pictures. One must understand why one is imaging a particular location, what information one is trying to obtain, and even more importantly, what information is not being obtained with the particular camera location/lens combination.

\section{Acknowledgements}

The assistance and rapid response to inquiries by Jason Birch of Adam Technology is noted, as is Tony Loschiavo's (Chief Mine Engineer, Tahera Diamond Corp, Jericho Mine) assistance with mine access, current plans and models, and general comments. Without their assistance, this work would not have been accomplished.

The permission of Tahera Diamond Corporation, who allowed this document to be published, is also gratefully acknowledged.

\section{References}

Mathis, J.I. and Todd, J.K. (2002) Improving double bench face performance at the Ekati diamond mine, Presented at the CIM convention, Vancouver, B.C., Canada, April 2002.

Mathis, J.I. (2002) Bench face design in rock. http://www.edumine.com.

Mathis, J.I. (1988) Development and verification of a three-dimensional rock joint model. Doctoral Thesis 1988:63 D, University of Luleå, Sweden, May. 